\title{
Separation and Purification of Sulforaphane from Broccoli by Solid Phase Extraction
}

\section{Dandan Han and Kyung Ho Row *}

Department of Chemical Engineering, Inha University, 253 Yonghyun-Dong, Nam-Ku, Incheon 402-751, Korea; E-Mail: hdd_216@hotmail.com

* Author to whom correspondence should be addressed; E-Mail: rowkho@inha.ac.kr; Tel.: +82-32-860-7470; Fax: +82-32-872-0959.

Received: 10 February 2011; in revised form: 1 March 2011 / Accepted: 7 March 2011 / Published: 10 March 2011

\begin{abstract}
A simple solid-phase extraction (SPE) method for the determination of sulforaphane in broccoli has been developed. The optimal conditions were found to be use of a silica SPE cartridge, and ethyl acetate and dichloromethane as washing and eluting solvents, respectively, which could eliminate interferences originating from the broccoli matrix. The extracts were sufficiently clean to be directly injected into high-performance liquid chromatography (HPLC) for further chromatographic analysis. Good linearity was obtained from 0.05 to $200 \mu \mathrm{g} / \mathrm{mL}(\mathrm{r}=0.998)$ for sulforaphane with the relative standard deviations less than $3.6 \%$. The mean recoveries of sulforaphane from broccoli were more than $90.8 \%$ and the detection limit $(\mathrm{S} / \mathrm{N}=3: 1)$ was $0.02 \mu \mathrm{g} / \mathrm{mL}$. The SPE method provides a higher yield of sulforaphane from crude extracts compared to conventional liquid-liquid extraction.
\end{abstract}

Keywords: broccoli; sulforaphane; solid-phase extraction

\section{Introduction}

Broccoli is a famous vegetable around the world, belonging to the cruciferous family, which is rich in antioxidants such as vitamin $\mathrm{C}$, quercetin and kaempferol [1,2]. Medicinal studies have shown that increasing consumption of broccoli can lower the risk of breast [3], skin [4] and prostate [5] cancers. Recent research showed that glucoraphanin (4-methylsulfinybutyl glucosinolate) is another important constituent in broccoli and it can produces sulforaphane when hydrolyzed by myrosinase. 
Sulforaphane (Figure 1) has attracted researchers' attention as a promising cancer chemopreventive agent [6]. In many studies, sulforaphane can reduce the incidence of a number of forms of tumor [7-10]. It is important to develop a rapid and simple method for determination and separation of sulforaphane from broccoli. Several analytical methods such as high-performance liquid chromatography (HPLC) [11,12], GC/mass spectrometry [13] and evaporative light-scattering [14] have been used to determine sulforaphane in broccoli. Meanwhile, preparative HPLC [15] and high-speed countercurrent chromatography [16] have been used to purify sulforaphane. However, the enzymatic hydrolysis of glucoraphanin generates a variety of compounds (glucose, sulfate, isothiocyanates, thiocyanates, nitriles) which interfere with the separation and determination of sulforaphane. Therefore, it is necessary to establish a simple and convenient method for the selective extraction and separation of sulforaphane from broccoli.

In this study, the interference of different hydrolysates was removed by choosing the optimum $\mathrm{pH}$ and three different kinds of solid-phase extraction cartridges were used to purify sulforaphane.

Figure 1. The molecular structure of sulforaphane in broccoli.

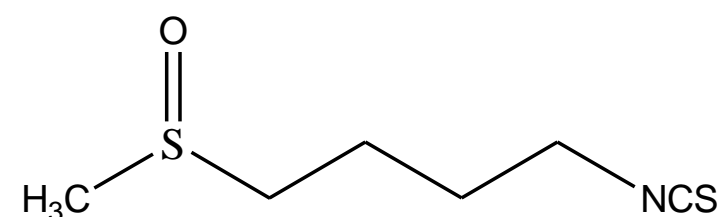

\section{Results and Discussion}

\subsection{Optimization of Chromatographic Conditions}

Selection of optimal HPLC conditions is important for the determination and separation of suforaphane. In this study, different wavelengths (205 nm, $235 \mathrm{~nm}$ and $254 \mathrm{~nm}$ ) were investigated, and the results showed sulforaphane had largest absorbance under $205 \mathrm{~nm}$. Therefore, $205 \mathrm{~nm}$ was chosen for further analyses.

Different kinds of mobile phases such as methanol, acetonitrile, and different concentrations of methanol $/ \mathrm{H}_{2} \mathrm{O}$ and acetonitrile $/ \mathrm{H}_{2} \mathrm{O}$ were investigated. Under $205 \mathrm{~nm}$, methanol has strong background absorbance, which is difficult to balance the $\mathrm{C}_{18}$ column. The $20 \%$ acetonitrile/ $\mathrm{H}_{2} \mathrm{O}$ (v/v) was proved to provide the best separation, because there is no interference of other impurities and the retention time of sulforaphane is short. The chromatogram of sulforaphane is shown in Figure 2.

\subsection{Optimization of the Hydrolyzation from Glucoraphanin to Sulforaphane}

To optimize the hydrolysis of glucoraphanin to sulforaphane in fresh broccoli, preliminary trials were conducted with different $\mathrm{pHs}$ of acidic water (3, 4, 5 and 6), and hydrolysis times (2, 4 and $6 \mathrm{~h}$ ). The incubation temperature was constant at $35{ }^{\circ} \mathrm{C}$. Table 1 shows that the resulting sulforaphane amount was highest with $\mathrm{pH} 3.0$ and hydrolysis time $4 \mathrm{~h}$. 
Figure 2. Chromatogram of standard sulforaphane. (Mobile phase: acetonitrile/water (20/80, v/v), injection volume: $10 \mu \mathrm{L}$, detection wavelength: $205 \mathrm{~nm}$ ).

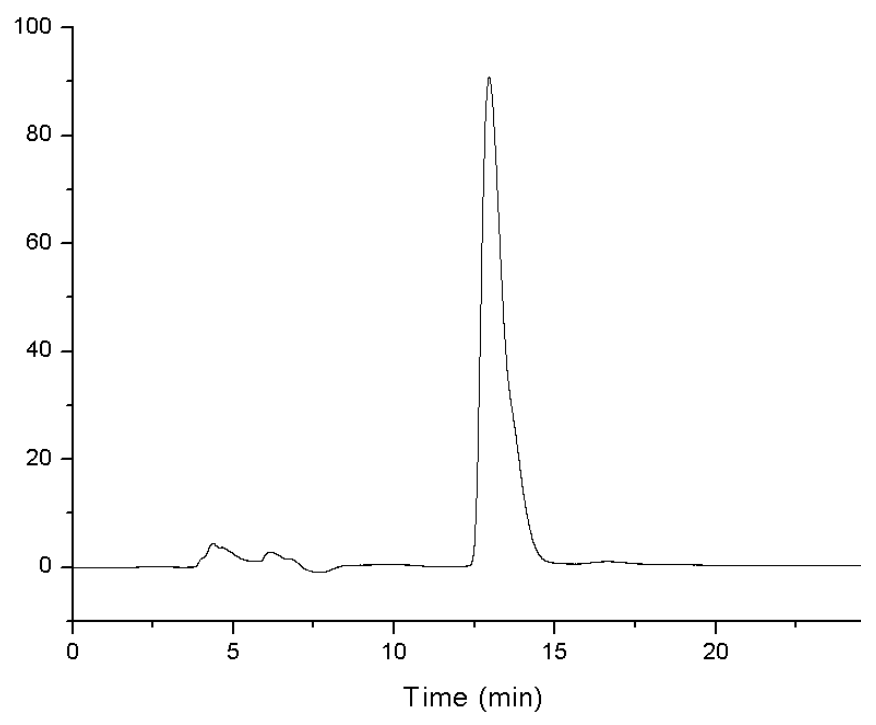

Table 1. The amount of extracted sulforaphane under different $\mathrm{pH}$ conditions.

\begin{tabular}{cc}
\hline $\mathbf{p H}$ & Amount of sulforaphane (mg/g) \\
\hline 0 & 0.024 \\
2.0 & 0.057 \\
3.0 & 0.148 \\
4.0 & 0.132 \\
6.0 & 0.118 \\
\hline
\end{tabular}

\subsection{Optimization of SPE Conditions}

\subsubsection{Choice of Different SPE Cartridges}

In this study, three kinds of SPE cartridges $\left(\mathrm{C}_{18}\right.$, amino and silica) were used, and the elution amount with different solvents are shown in Table 2. These data show that the silica cartridge is better than the other two cartridges for extracting sulforaphane. This may be attributed to the weak polarity of sulforaphane, which be easily selectively absorbed by a weak polarity column.

Table 2. Extracted amounts of sulforaphane when using different solvents in the washing step and with different cartridges.

\begin{tabular}{cccc}
\hline \multirow{2}{*}{ Washing solvent } & \multicolumn{3}{c}{ Amount of sulforaphane (mg/g) } \\
\cline { 2 - 4 } & Silica cartridge & $\mathbf{C}_{\mathbf{1 8}}$ cartridge & Amino cartridge \\
\hline Water & 0.016 & 0.003 & 0.002 \\
Acetonitrile & 0.069 & 0.032 & 0.027 \\
Dichloromethane & 0.357 & - & 0.057 \\
0.1M Acetic acid & - & 0.062 & - \\
Hexane & - & - & 0.006 \\
Ethyl acetate & 0 & 0 & - \\
\hline \multicolumn{4}{c}{}
\end{tabular}




\subsubsection{Influence of the Washing Solvent and Elution Solvent}

In the SPE, selection of an appropriate washing solvent and elution solvent is the first factor that should be considered because it has a direct effect on desorption efficiency. Different washing and eluting steps were investigated to optimize the process of selective extraction. It is important to apply a washing step immediately after loading the extract from plants on the sorbent, as it can reduce most of the interference during the separation of the analyte. Initially, different washing solvents with different polarity (water, acetonitrile, dichloromethane and ethyl acetate) were investigated. Table 2 shows that sulforaphane was not washed out by ethyl acetate, while some unnecessary compounds were. Therefore, ethyl acetate was selected as a suitable washing solvent. Moreover, sulforaphane could be washed out simultaneously with a large amount of unnecessary compounds when water, acetonitrile, and dichloromethane were used, where the largest relative amount of sulforaphane was washed out by dichloromethane. Therefore, dichloromethane was used as the elution solvent in subsequent steps.

\subsubsection{Influence of Elution Solvent Volume}

The volume of elution solvent is another factor that should be considered. A series of experiments were designed and this factor was investigated by changing the volume of the elution solvent from 2 to $6 \mathrm{~mL}$. As shown in Table 3, it can be observed that the extraction amount of sulforaphane increased with increasing volumes of dichloromethane from 2 and $6 \mathrm{~mL}$. When the volume of dichloromethane exceeded $4 \mathrm{~mL}$, the amount of sulforaphane remained almost constant. Therefore, in subsequent experiments, $4 \mathrm{~mL}$ of dichloromethane was selected.

Table 3. Extracted amounts of sulforaphane by different volumes of dichloromethane in the elution step (Silica cartridge).

\begin{tabular}{cc}
\hline Volume of dichloromethane $(\mathbf{m L})$ & Amount of sulforaphane $(\mathbf{m g} / \mathbf{g})$ \\
\hline 2 & 0.120 \\
3 & 0.214 \\
4 & 0.324 \\
5 & 0.326 \\
6 & 0.327 \\
\hline
\end{tabular}

\subsubsection{Validation of the Proposed Method}

A series of standard solutions containing sulforaphane at six concentrations were obtained by mixing the appropriate amount of stock solution $(1 \mathrm{mg} / \mathrm{mL})$. Each concentration was analyzed in triplicate. The results are listed in Table 4. The detection limit $(\mathrm{S} / \mathrm{N}=3: 1)$ was $0.02 \mu \mathrm{g} / \mathrm{mL}$ for sulforaphane, while for other methods it was usually higher than $1 \mu \mathrm{g} / \mathrm{mL}$ [17]. The results showed good precision with a relative standard deviation (RSD) for sulforaphane of $3.54 \%$.

The developed SPE-HPLC method was applied successfully to the analysis of sulforaphane from broccoli under the optimum conditions. Figure 3 shows the chromatograms of broccoli when extraction was performed by silica cartidge. Table 5 shows the contents of sulforaphane and recoveries in broccoli. 
Table 4. Calibration range $(n=5)$ and LOQ for the quantification of sulforaphane.

\begin{tabular}{cccc}
\hline Target compound & Linear range $(\boldsymbol{\mu g} / \mathbf{m L})$ & $\boldsymbol{r}^{2}$ & $\mathbf{L O D}(\boldsymbol{\mu g} / \mathbf{m L})$ \\
\hline Sulforaphane & $0.05-200$ & 0.998 & 0.002 \\
\hline
\end{tabular}

Figure 3. Chromatogram of broccoli extracted by silica-SPE (Injection volume: $10 \mu \mathrm{L}$ ).

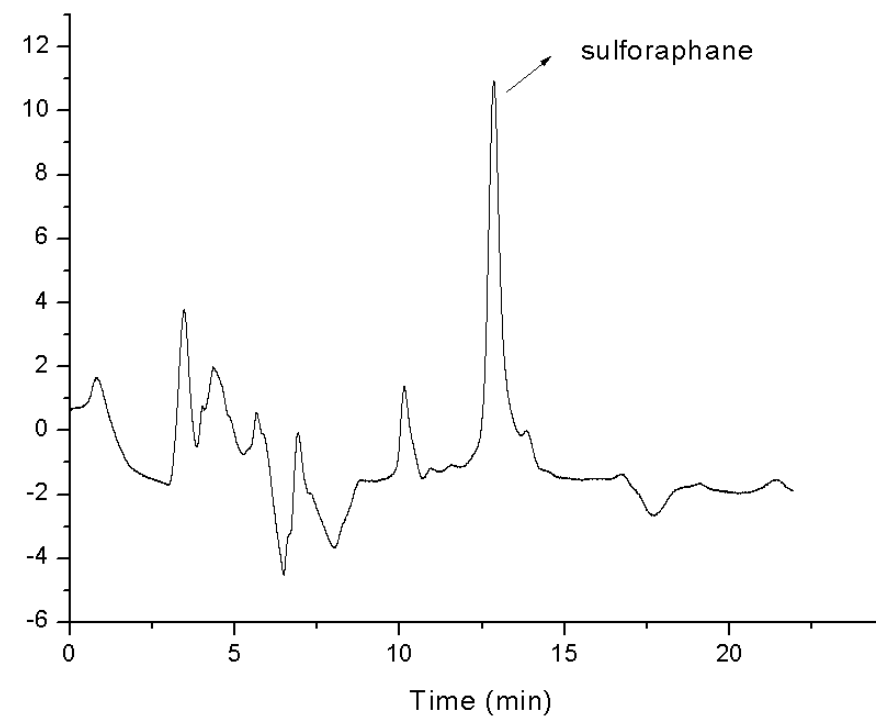

Table 5. Recovery of sulforaphane in three concentration levels.

\begin{tabular}{cccccc}
\hline & $\begin{array}{c}\text { Original } \\
(\boldsymbol{\mu} \mathbf{g} / \mathbf{m g})\end{array}$ & $\begin{array}{c}\text { Add amount } \\
(\boldsymbol{\mu g} / \mathbf{m g})\end{array}$ & $\begin{array}{c}\text { Found amount } \\
(\boldsymbol{\mu} \mathbf{g} / \mathbf{m g})\end{array}$ & Recovery $(\boldsymbol{\%})$ & RSD \\
\hline Sulforaphane & 0.513 & 10.0 & 9.59 & 90.8 & 3.54 \\
& 0.513 & 50.0 & 47.10 & 93.2 & 3.17 \\
& 0.513 & 100.0 & 96.91 & 96.4 & 2.36 \\
\hline
\end{tabular}

\section{Experimental Section}

\subsection{Reagents and Materials}

Sulforaphane was obtained from Sigma-Aldrich (USA), and used without further purification. Acetonitrile, methanol, ethyl acetate and dichloromethane were obtained from Duksan Pure Chemical Co., LTD (Ansan, Korea). All the other reagents used in the experiment were HPLC or analytical grade. Double distilled water was filtered with a vacuum pump (Division of Millipore, Waters, USA) and filter (HA-0.45, Division of Millipore, Waters, USA) before use. All the samples were filtered by using a filter (MFS-25, $0.2 \mu \mathrm{m}$ TF, WHATMAN, USA) before injection into the HPLC system. Stock standard solutions of sulforaphane were prepared by dissolving $10 \mathrm{mg}$ of standards in $10 \mathrm{~mL}$ of acetonitrile. Commercial $\mathrm{C}_{18}$, amino and silica cartridge $(200 \mathrm{mg} / 3 \mathrm{~mL})$ were purchased from Alltech (USA).

\subsection{Chromatographic Conditions}

Chromatography was performed with a Waters $600 \mathrm{~s}$ multisolvent delivery system, a Waters 616 liquid chromatography, and a Waters 2487 variable wavelength, dual-channel, UV detector (Waters 
Associates, Milford, MA, USA). A six-port Rheodyne injector (20 $\mu \mathrm{L}$ sample loop) was also used. Data processing was performed with Millennium 3.2 software resident in an HP Vectra 500PC. Compounds were separated on a $250 \mathrm{~mm} \times 4.6 \mathrm{~mm}, 5-\mu \mathrm{m}$ particle, OptimaPak $\mathrm{C}_{18}$ column (RS Tech, Daejeon, Korea). HPLC separation of sulforaphane was conducted by using acetonitrile/ $\mathrm{H}_{2} \mathrm{O}$ $(20 / 80, \mathrm{v} / \mathrm{v})$ as mobile phase at a flow rate of $0.5 \mathrm{~mL} / \mathrm{min}$ and the detection was carried out at a wavelength of $205 \mathrm{~nm}$. Distilled water was filtered with a vacuum pump and filter (HA-0.45 $\mu \mathrm{m}$; Millipore, Waters, USA) before use.

\subsection{Sample Clean-up and Preparation by SPE}

Fresh broccoli was pulverized and $5 \mathrm{~g}$ of the resultant powder was weighed and extracted with $20 \mathrm{~mL}$ of different $\mathrm{pH}$ of hydrochloric acid $(\mathrm{HCl})$ for $2 \mathrm{~h}$. The resulting mixture was extracted 3 times with $20 \mathrm{~mL}$ of dichloromethane, which was combined and salted with anhydrous sodium sulfate. The dichloromethane fraction was dried at $30{ }^{\circ} \mathrm{C}$ under vacuum on a rotary evaporator. The residue was dissolved in acetonitrile and was then filtered through a $0.22 \mathrm{~mm}$ membrane filter for the following study. The sulforaphane was purified with different SPE cartridge. Prior to use, the silica cartridge was conditioned with $4 \mathrm{~mL}$ of dichoromethane, the $\mathrm{C}_{18}$ cartridge was conditioned with $4 \mathrm{~mL}$ methanol and amino cartridge was conditioned with $4 \mathrm{~mL}$ ethyl acetate. First, $200 \mu \mathrm{L}$ of organic extract was loaded through the three different kinds cartridges, then the silica cartridge was washed with $4.0 \mathrm{~mL}$ of ethyl acetate (which was then discarded) and the sulforaphane eluted with $4 \mathrm{~mL}$ of dichloromethane; the $\mathrm{C}_{18}$ cartridge was washed with $4 \mathrm{~mL}$ of water (which was then discarded) and the sulforaphane eluted with $4 \mathrm{~mL}$ of $0.1 \mathrm{~mol} / \mathrm{L}$ of acetic acid; and the amino cartridge was washed with 4 $\mathrm{mL}$ of ethyl acetate (which was then discarded) and the sulforaphane eluted with $4 \mathrm{~mL}$ dichloromethane. The obtained extractants were evaporated to dryness in a vacuum oven at $45{ }^{\circ} \mathrm{C}$ for $2 \mathrm{~h}$, and redissolved with $2 \mathrm{~mL}$ of acetonitrile. The resulting solutions were vortexed for $30 \mathrm{~s}$ and filtered with a membrane of $0.45 \mu \mathrm{m} .10 \mu \mathrm{L}$ samples of these solutions were then injected into the column of the HPLC system. All samples were analyzed in duplicate.

\section{Conclusions}

A simple and sensitive SPE-HPLC assay procedure was developed for the extraction and determination of sulforaphane from broccoli. The absorption wavelength was determined at $205 \mathrm{~nm}$. The elution mobile phase was $\mathrm{ACN} / \mathrm{H}_{2} \mathrm{O}\left(20: 80\right.$, v/v). Compared with $\mathrm{C}_{18}$ and amino cartridges, the silica cartridge displayed better selectivity to sulforaphane. Ethyl acetate was used as a washing solvent, and $4 \mathrm{~mL}$ of dichloromethane as an elution solvent. The extracted amount of sulforaphane from broccoli was $0.513 \mathrm{mg} / \mathrm{g}$.

\section{Acknowledgements}

This research was supported by Basic Science Research Program through the National Research Foundation (NRF) of Korea funded by the Ministry of Education, Science and Technology (2011-0002642). 


\section{References}

1. Vallejo, F.; Tomás-Barberán, F.A.; Garcia-Viguera, C. Glucoraphanins and vitamin C content in edible parts of broccoli florets after domestic cooking. Eur. Food Res. Tech. 2002, 215, 310-316.

2. Koh, E.; Wimalasiri, K.M.S.; Chassy, A.W.; Mitchell, A.E. Content of ascorbic acid, quercetin, kaempferol and total phenolics in commercial broccoli. J. Food Compos. Anal. 2009, 22, 637-643.

3. Chen, Y.J.D.; Conte, J.; Lin, Y.; Gemelli, A.; Castro, A.; Yarlagadda, S.; Gonzalez, S.; Philips, N. Sulforaphane, an extract from broccoli, prevents skin cancer. J. Plast. Dermatol. 2008, 4, 165-166.

4. Rose, P.; Huang, Q.; Ong, C.N.; Whiteman, M. Broccoli and watercress suppress matrix metalloproteinase-9 activity and invasiveness of human MDA-MB-231 breast cancer cells. Toxicol. Appl. Pharmacol. 2005, 209, 105-113.

5. Canene-Adams, K.; Lindshield, B.L.; Wang, S.; Jeffery, E.H.; Clinton, S.K.; Erdman, J.W., Jr. Combinations of tomato and broccoli enhance antitumor activity in dunning R3327-H prostate adenocarcinomas. Cancer Res. 2007, 67, 836-843.

6. Sharma, R.; Sharma, A.; Chaudhary, P.; Pearce, V.; Vatsyayan, R.; Singh, S.V.; Awasthi, S.; Awasthi, Y.C. Role of lipid peroxidation in cellular responses to D,L-sulforaphane, a promising cancer chemopreventive agent. Biochemistry 2010, 49, 3191-3202.

7. Hahm, E.R.; Singh, S.V. Sulforaphane inhibits constitutive and interleukin-6-induced activation of signal transducer and activator of transcription 3 in prostate cancer cells. Cancer Prev. Res. 2010, 3, 484-494.

8. Rausch, V.; Liu, L.; Kallifatidis, G.; Baumann, B.; Mattern, J.; Gladkich, J.; Wirth, T.; Schemmer, P.; Büchler, M.W.; Zöller, M.; Salnikov, A.V.; Herr, I. Synergistic activity of sorafenib and sulforaphane abolishes pancreatic cancer stem cell characteristics. Cancer Res. 2010, 70, 5004-5013.

9. Dickinson, S.E.; Melton, T.F.; Olson, E.R.; Zhang, J.; Saboda, K.; Bowden, G.T. Inhibition of activator protein-1 by sulforaphane involve interaction with cysteine in the cFos DNA-binding domain: Implications for chemoprevention of UVB-induced skin cancer. Cancer Res. 2009, 69, 7103-7110.

10. Rudolf, E.; Andělová, H.; Červinka, M. Activation of several concurrent proapoptic pathways by sulforaphane in human colon cancer cells SW620. Food Chem. Toxicol. 2009, 47, 2366-2373.

11. Agrawal, S.; Winnik, B.; Buckley, B.; Mi, L.; Chung, F.L.; Cook, T.J. Simultaneous determination of sulforaphane and its major metabolites from biological matrices with liquid chromatographytandem mass spectroscopy. J. Chrom. B 2006, 840, 99-107.

12. Liang, H.; Yuan, Q.P.; Dong, H.R.; Liu, Y.M. Determination of sulforaphane in broccoli and cabbage by high-performance liquid chromatography. J. Food Compos. Anal. 2006, 19, 473-476.

13. Chiang, W.C.K.; Pusateri, J.; Leitz, R.E.A. Gas chromatography/mass spectrometry method for the determination of sulforaphane and sulforaphane nitrile in broccoli. J. Agr. Food Chem. 1998, 46, 1018-1021.

14. Nakagawa, K.; Umeda, T.; Higuchi, O.; Tsuzuki, T; Suzuki, T.; Miyazawa, T. Evaporative light-scattering analysis of sulforaphane in broccoli samples: Quality of broccoli products regarding sulforaphane contents. J. Agr. Food Chem. 2006, 54, 2479-2483. 
15. Matusheski, N.V.; Walling, M.A.; Juvic, J.A.; Klein, B.P.; Kushad, M.M.; Jeffery, E.H. Preparative HPLC method for the purification of sulforaphane and sulforaphane nitrile from Brassica oleracea. J. Agr. Food Chem. 2001, 49, 1867-1872.

16. Liang, H.; Li, C.; Yuan, Q.; Vriesekoop, F. Application of high-speed countercurrent chromatography for the isolation of sulforaphane from broccoli seed meal. J. Agr. Food Chem. 2008, 56, 7746-7749.

17. Campas-Baypoli, O.N.; Sánchez-Machado, D.I.; Bueno-Solano, C.; Ramírez-Wong, B.; López-Cervantes, J. HPLC method validation for measurement of sulforaphane level in broccoli by-products. Biomed. Chrom. 2010, 24, 387-392.

(C) 2011 by the authors; licensee MDPI, Basel, Switzerland. This article is an open access article distributed under the terms and conditions of the Creative Commons Attribution license (http://creativecommons.org/licenses/by/3.0/). 